\title{
Bases para la puesta en marcha de un modelo de recuperación ambiental del paisaje de Tierra de Campos (Castilla y León, España)
}

\author{
Blanco, $\mathrm{R}^{1^{*}}$, Navarro, $\mathrm{J}^{2}$ y Saiz, $\mathrm{A}^{3}$ \\ ${ }^{1}$ Servicio Territorial de Medio Ambiente de Palencia. Junta de Castilla y León. \\ Avda. Casado del Alisal, 27. 34001 Palencia. \\ ${ }^{2}$ Escuela Técnica Superior de Ingenierías Agrarias. Universidad de Valladolid. \\ Avda. de Madrid, 57. 34004 Palencia. \\ ${ }^{3}$ Centro Tecnológico ITAGRA. Escuela Técnica Superior de Ingenierías Agrarias de Palencia. \\ Avda. de Madrid, 57. 34004 Palencia.
}

*Autor para correspondencia: raul.blanco@jcyl.es

\section{Resumen}

Tierra de Campos es una comarca de unos $4400 \mathrm{~km}^{2}$, cuyas características son el dominio del cultivo agrícola herbáceo, la práctica ausencia de vegetación natural y un gran declive demográfico. Su paisaje es uno de los más representativos de las campiñas agrícolas cerealistas, tanto de Castilla y León como del conjunto de España. La agricultura intensiva y las concentraciones parcelarias lo han simplificado notablemente, reduciendo su calidad visual y biodiversidad. En este trabajo se exponen las alteraciones más significativas de este paisaje, entre las que destacan: la pérdida de vegetación natural, la irrupción de grandes naves en el entorno de los pueblos y la desaparición del patrimonio cultural edificado. Analizada su degradación secular, se propone un modelo de recuperación que contempla tres tratamientos generales: la restauración vegetal con árboles y arbustos, la integración paisajística de edificaciones e infraestructuras, y la restauración del patrimonio cultural. Para ello se definen 56 actuaciones en los 14 espacios degradados diagnosticados: 1) espacios agrícolas intensivos afectados por concentraciones parcelarias; 2) espacios afectados por transformaciones en regadío; 3) aquellos afectados por infraestructuras lineales de transporte; 4) los afectados por explotaciones mineras, préstamos y vertederos; 5) espacios afectados por infraestructuras energéticas; 6) ríos y arroyos desnaturalizados; 7) zonas húmedas degradadas; 8) vías pecuarias y del ferrocarril en desuso; 9) fuentes y parcelas públicas degradadas; 10) terrenos deforestados y/o erosionados; 11) escombreras y vertederos de residuos; 12) entorno de construcciones en suelo rústico; 13) periferias de los pueblos; y 14) pueblos descuidados y abandonados. Para conseguir su restauración, se seleccionan 32 árboles y 27 arbustos. Finalmente, se define la imagen objetivo de este paisaje agrícola, cuya recuperación conllevará un mayor arraigo y calidad de vida de sus habitantes y constituirá un recurso socioeconómico para la comarca.

Palabras clave: Restauración, Paisaje agrario, Paisaje cerealista, Diversificación agraria. 


\section{Introducción}

De forma sucinta, se puede considerar que el paisaje es la manifestación externa del territorio, aunque con matices según sean las disciplinas que se acerquen a esta materia. Existen dos enfoques básicos para su estudio: el ecológico (que tiene que ver con los procesos del medio) y el visual (relacionado con la percepción y la estética). El Convenio Europeo del Paisaje (Consejo de Europa, 2000) ratifica una concepción amplia del paisaje, como "cualquier parte del territorio tal como la percibe la población, cuyo carácter sea el resultado de la acción y la interacción de factores naturales y/o humanos".

Están documentados múltiples estudios que relacionan directamente un paisaje de alta calidad ligado a la naturaleza con la mejora del estado anímico de las personas, con su calidad de vida, bienestar y salud. En ellos suele haber coincidencia en señalar el importante valor de la vegetación y del agua, así como del orden en su configuración (González Bernáldez, 1990; Corraliza, 1993; Vallerani, 2008).

El paisaje rural, definido como el espacio que no es natural ni urbano, tiene una gran importancia tanto en valor superficial como funcional (Bolós, 2005). Dentro de él, el agrícola ha sufrido una gran transformación en la segunda mitad del siglo pasado, como consecuencia de su tecnificación, pasando a ser un paisaje mucho más simplificado y degradado; el caso más extremo se da en el paisaje cerealista, donde prima la producción a gran escala con una gran pérdida de vegetación natural y modificación de las masas de agua naturales. El Atlas de los Paisajes de España (Mata y Sanz, 2004) encuadra este tipo de paisaje en la asociación Campiñas, que ocupa una considerable extensión tanto en España (5 676000 ha), como en Castilla y León (2 150000 ha). El Paisaje de Campiñas de Tierra de Campos es la unidad paradigmática de paisajes cerealistas y la que caracteriza a la comarca objeto de este estudio.

Dado que el análisis histórico del territorio estudiado muestra una clara devastación paisajística (Blanco, 2016), en este trabajo se ha pretendido definir las líneas generales que contribuirían a su protección, mejora y recuperación. En primer lugar, conviene destacar que la recuperación ambiental o recuperación de espacios degradados es la técnica para reconvertir espacios cuyo estado es insatisfactorio por otros que nos satisfagan (Gómez Orea, 2004). Por ello es el instrumento curativo fundamental para corregir impactos y mejorar la calidad del paisaje de Tierra de Campos, así como una oportunidad para afrontar la despoblación actual y promover su desarrollo económico. Por otro lado, la diversificación del paisaje agrario es otro instrumento fundamental para mejorar la calidad del paisaje de Tierra de Campos. En nuestra zona se ha visto que las tres acciones prioritarias son (Blanco, 2016) a través de la creación de setos vivos, sotos y bosques isla (De Andrés et al., 2003; Rey Benayas, et al., 2008; Rey Benayas, 2012). Las medidas de condicionalidad de la Política Agraria Común y la forestación de tierras agrarias son unas adecuadas herramientas para llevarla a cabo.

En otro sentido, hay muchos aspectos para valorizar el paisaje de Tierra de Campos, tanto en los espacios urbanos de los pueblos (cascos históricos, parques y jardines, parques periurbanos) como en los espacios rústicos (áreas recreativas, ermitas, 
senderos y caminos, miradores, centros de interpretación de la naturaleza, observatorios de avifauna) (Blanco, 2016).

Adicionalmente, los instrumentos preventivos de gestión ambiental son unas eficaces herramientas para la protección del paisaje; particularmente interesantes en Tierra de Campos son la planificación urbanística, la calificación ambiental y la evaluación de impacto ambiental de proyectos (Blanco, 2016). Con estas herramientas se asegura la protección y persistencia de la imagen objetivo alcanzada con el resto de medidas.

\section{Objetivos}

El objetivo general de este estudio es la definición de un modelo de recuperación ambiental del paisaje de Tierra de Campos. Los principales objetivos particulares son los siguientes:

1. Caracterizar el paisaje de Tierra de Campos

2. Diagnosticar sus deterioros

3. Definir las actuaciones de recuperación ambiental aplicables a cada tipo de espacio degradado de Tierra de Campos

4. Seleccionar un listado de árboles y arbustos apropiados para la recuperación ambiental

5. Aportar una imagen objetivo del paisaje de calidad de Tierra de Campos que pueda ser promocionada y protegida.

\section{Zona de estudio}

Tierra de Campos es una comarca natural con una superficie aproximada de 4400 $\mathrm{km}^{2}$, cuyos límites se extienden por las provincias de Palencia, Valladolid, Zamora y, en menor medida, León (Figura 1). Desde el punto de la geomorfología, Tierra de Campos está constituida básicamente por campiñas -llanuras suavemente onduladaslimitadas por los páramos detríticos al norte y los calcáreos al sur (Vaca, 1992).

El clima es netamente continental, con inviernos frescos y fríos y veranos secos y cálidos; otoño y primavera presentan rasgos más benignos. Las precipitaciones oscilan entre los 400 y $450 \mathrm{~mm}$ anuales.

En cuanto a la hidrografía, se distinguen dos grandes grupos de ríos: Cea, Carrión y Pisuerga (con grandes caudales) y Salado, Valderaduey, Sequillo, Valdeginate, Cueza y Ucieza (caudales irregulares muy inferiores, encauzados y rectificados). A ellos hay que sumarle una tupida red de arroyos intermitentes que también, en su mayoría, han sido encauzados. Una buena parte de las lagunas que antaño abundaban en la comarca han sido drenadas. Dentro de los varios canales construidos en la comarca, destaca de modo singular el Canal de Castilla.

En relación con los suelos, cabe señalar que en Tierra de Campos dominan los pardocalizos. Tienen un bajo contenido en materia orgánica y nitrógeno, siendo arcillosos y básicos. 


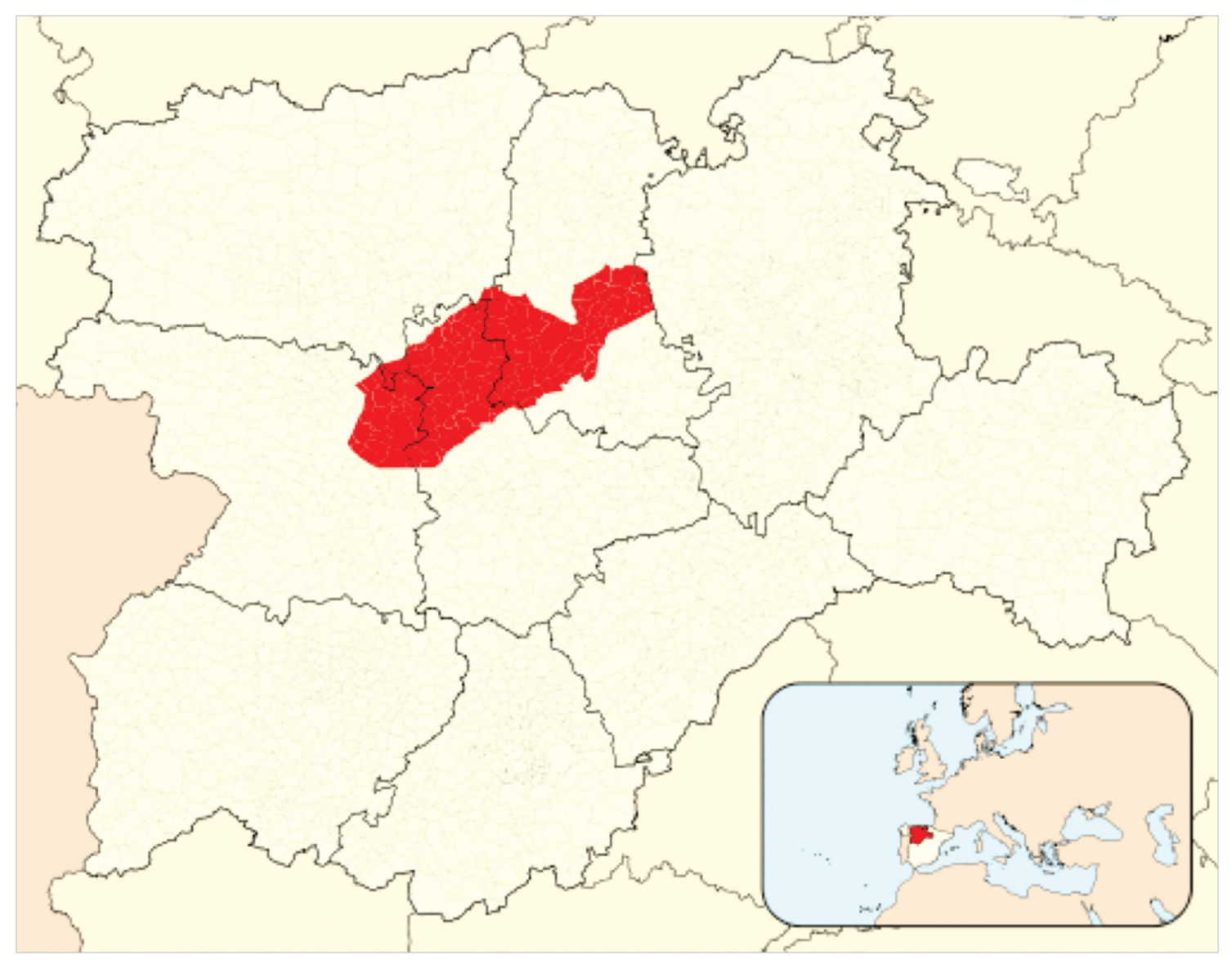

Figura 1. Mapa de Tierra de Campos realizado a partir de la delimitación de González Garrido (1941).

La vegetación climácica en la comarca son los bosques de encina, con franjas de vegetación ripícola en las riberas de ríos y arroyos. Este bosque primitivo fue talado para su cultivo desde varios siglos antes de Cristo, de forma que actualmente quedan minúsculos retazos de lo que fue. Aun así, durante varios siglos el paisaje agrícola estuvo acompañado de una gran variedad de árboles y arbustos que conformaban un auténtico mosaico. El cambio de una agricultura tradicional a otra productivista, a mediados del siglo pasado, y las concentraciones parcelarias ocasionaron una simplificación de este paisaje diverso, de modo que árboles y arbustos desaparecieron o quedaron relegados a zonas marginales (Oria de Rueda, 2007).

La fauna de Tierra de Campos está adaptada al hábitat cerealista, de forma que el grupo más representativo es el de las aves esteparias, con la avutarda a la cabeza. En esta comarca nidifica una de las poblaciones más numerosas de esta especie protegida de la Península Ibérica. Una parte importante de Tierra de Campos está declarada espacio natural, bien sea como laguna y entorno (Villafáfila y la Nava, como principales) o bien como hábitat de especies de avifauna cerealista (Zonas de Especial Protección para las Aves, ZEPA). También están protegidas las riberas de los ríos principales, Cea y Carrión.

Del análisis socioeconómico hay que destacar sin lugar a dudas el éxodo rural que 
sufre la comarca desde 1950, que ha hecho reducir la población de Tierra de Campos en un $70 \%$ y que, por desgracia, aún se mantiene (Blanco, 2016). Además se trata de una población muy envejecida, con mentalidad inmovilista y baja capacidad para emprender.

La arquitectura tradicional se corresponde con el tipo de "Núcleos en origen cercados, de disposición continua y edificación con corral posterior", que usa como materiales básicos el barro, la madera y la teja curva árabe (Benito, 1998). El elemento singular que más caracteriza a Tierra de Campos es el palomar, de gran valor estético y perfecta integración en el paisaje.

Tierra de Campos cuenta con un magnífico patrimonio histórico-artístico, sobre todo de arquitectura monumental religiosa. En todos los pueblos hay una o varias iglesias, que destacan entre el caserío. Los estilos artísticos fundamentales son el románico, el gótico y el renacentista, con la singularidad de sus variantes mudéjares (Blanco, 2016).

\section{Material y métodos}

1. Análisis y valoración de fuentes documentales, priorizando las relativas al territorio.

2. Utilización del gvSIG como sistema de información geográfica de uso gratuito, apoyado en capas del SIGMENA (SIG de Medio Natural de Castilla y León) y en ortofotografías basadas en vuelos actuales y antiguos.

3. Empleo de una base de datos de más de 4000 fotografías, ilustrativas de las diversas características del territorio y de las actuaciones que en él tienen lugar.

4. Análisis de proyectos representativos de obras que afectan al paisaje de Tierra de Campos (proyecto, condicionantes ambientales, seguimiento obra y ambiental):

- Concentración parcelaria Herrín de Campos y 3 más.

- Transformación en regadío del sector IV Esla Campos.

- Explotación de ganado ovino en Ampudia.

- Explotación de ganado ovino en Cisneros.

- Variante de carretera de Villada.

- Préstamo PR-1 ferrocarril alta velocidad, Becerril de Campos.

- Línea eléctrica aérea de alta tensión Ampudia-Grijota.

- Parque eólico El Castre, en Torremormojón.

- Polígono industrial sector 1 en Paredes de Nava.

5. Análisis de proyectos de recuperación ambiental singulares en Tierra de Campos (proyecto y seguimiento ambiental):

- Plantaciones, área de descanso y tramo accesible en el Camino de Santiago.

- Repoblación forestal parcela sobrante de vía pecuaria, Herrín de Campos. 
- Repoblación forestal de laderas en Ampudia.

- Repoblación forestal parcela de masa común, Frechilla.

- Restauración hidrológico-forestal y tratamientos posteriores, Medina de Rioseco.

- Recuperación ambiental y adecuación “Ruta de los Parques” en Villalón de Campos.

- Adecuación de camino turístico en Tamariz de Campos.

- Rehabilitación de antigua vía del ferrocarril como Vía Verde "Tierra de Campos".

- Restauración del arroyo Berruez en Villalón de Campos.

6. Realización de Recorridos paisajísticos por Villalón de Campos, mediante 34 transectos a lo largo de un año completo (junio 2013 - mayo 2014), abarcando la práctica totalidad de su término municipal. Con ello se ha caracterizado la matriz de Tierra de Campos no afectada por grandes proyectos.

\section{Resultados y discusión}

Del análisis realizado se concluye que el paisaje de campiñas de Tierra de Campos está caracterizado como una extensa llanura suavemente ondulada, con un uso abrumadoramente agrícola (cerealista) y la presencia de pequeños núcleos compactos. Su dinámica está marcada por el cambio de la agricultura tradicional a la intensiva, que se va acentuando con el paso del tiempo, así como por la simplificación y regularización del territorio como consecuencia de las concentraciones parcelarias. Dentro de la percepción visual del paisaje, destacan los contrastes cromáticos de los cultivos; los paisajes panorámicos con formas horizontales y líneas rectas (Figura 2); una calidad visual media-baja (basada en una carencia de geoformas significativas y singulares, masas de agua de escasas dimensiones, bosques escasos y básicamente monoespecíficos) y, finalmente, una fragilidad alta que propicia la generación de impactos visuales significativos. En cuanto a la ecología del paisaje de Tierra de Campos, se ha podido definir como la presencia de una matriz agrícola dominante, con manchas naturales excepcionales y corredores muy escasos; la conectividad del paisaje resulta ser muy reducida, siendo baja la biodiversidad.

En el estudio se han detectado 8 impactos significativos de grandes obras a escala comarcal, así como 28 degradaciones paisajísticas a escala municipal. Los tres deterioros más característicos del paisaje de Tierra de Campos son: la pérdida de vegetación natural, hasta considerarse prácticamente testimonial; el cambio de las características visuales básicas, debido fundamentalmente a la irrupción de grandes naves en el entorno de los pueblos y la destrucción del patrimonio cultural edificado, tanto histórico-artístico como arquitectónico popular.

El modelo de recuperación ambiental del paisaje de Tierra de Campos que se plantea se fundamenta en una serie de tratamientos generales, entre los que destacamos tres (Blanco, 2016): la restauración vegetal con árboles y arbustos; la restitución 


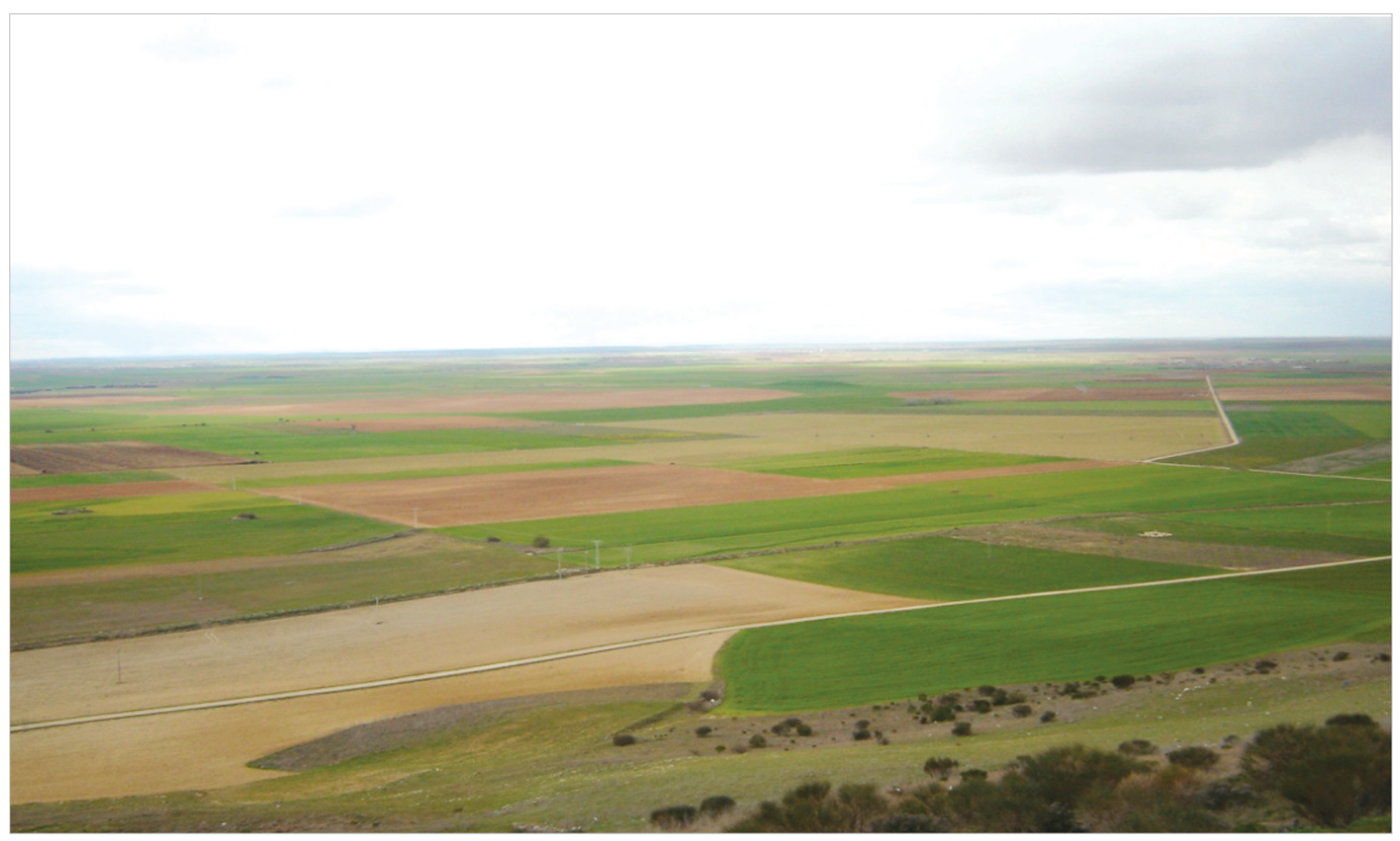

Figura 2. Paisaje panorámico de Tierra de Campos desde la muralla de Urueña.

o mejora de los atributos de calidad (en especial el patrimonio cultural) y la integración de los nuevos componentes edificados. Se han identificado 14 espacios degradados tipo en los que se plantean un total de 56 actuaciones (Tabla 1). Hay que tener en cuenta que la recuperación es perfectamente viable, pues del análisis realizado se ha comprobado que su presupuesto medio representa el 3,48 \% del relativo a los proyectos de construcción evaluados.

Tabla 1. Actuaciones de recuperación ambiental planteadas en los espacios degradados de Tierra de Campos.

1. Espacios con agricultura intensiva afectados por concentraciones parcelarias.

- Restauración vegetal de márgenes de caminos.

- Restauración vegetal de arroyos y regueras.

- Restauración vegetal de parcelas sobrantes.

- Plantaciones de diversificación en las parcelas agrícolas.

2. Espacios afectados por transformaciones en regadío.

- Restauración vegetal de márgenes de canales.

- Creación de senderos por los caminos de servidumbres.

- Naturalización de balsas de riego.

- Creación de observatorios de avifauna en balsas de riego. 
- Integración paisajística de edificaciones ligadas al regadío.

3. Espacios afectados por infraestructuras lineales de transporte.

- Recuperación ambiental de zonas afectadas por autovías y nuevas carreteras.

- Recuperación ambiental de zonas afectadas por ferrocarriles de alta velocidad.

- Recuperación ambiental de zonas afectadas por ferrocarriles convencionales existentes.

- Recuperación paisajística de carreteras existentes.

4. Espacios afectados por explotaciones mineras, préstamos y vertederos.

- Restauración de extracciones.

- Restauración de vertederos.

5. Espacios afectados por infraestructuras energéticas.

- Ocultación parcial de huertos solares.

- Ocultación o integración de centros de transformación y subestaciones eléctricas.

- Restauración de las zonas ocupadas por aerogeneradores y apoyos de las líneas eléctricas.

- Restauración de márgenes de caminos de acceso.

- Integración de infraestructuras energéticas mediante plantaciones vegetales.

- Creación de miradores.

- Instalación de salvapájaros en las líneas eléctricas de alta tensión.

6. Ríos y arroyos desnaturalizados.

- Rehabilitación de ríos y arroyos desnaturalizados.

7. Zonas húmedas degradadas.

- Restauración de zonas húmedas.

8. Vías pecuarias y del ferrocarril sin uso.

- Restauración de cañadas y cordeles como grandes corredores ecológicos.

- Recuperación de veredas y pequeñas vías pecuarias.

- Rehabilitación como Vía Verde de las antiguas vías del ferrocarril.

9. Fuentes y pequeñas parcelas públicas degradadas.

- Restauración natural de fuentes. 
- Restauración forestal-natural de pequeñas parcelas públicas.

10. Espacios deforestados y/o erosionados.

- Restauración hidrológico-forestal de laderas desarboladas.

- Repoblación forestal de eriales y terrenos agrícolas marginales.

- Tratamientos selvícolas y plantaciones de diversificación en laderas repobladas.

11. Escombreras y vertederos de residuos.

- Restauración de vertederos de residuos.

- Restauración de escombreras.

- Restauración de espacios afectados por depósitos puntuales de escombros.

12. Entorno de construcciones en suelo rústico.

- Integración de paramentos y cubiertas.

- Realización de pantallas vegetales.

13. Periferias de los pueblos.

- Urbanización.

- Implantación de setos vegetales en vallas metálicas.

- Limpieza y recogida de residuos.

- Eliminación de elementos degradantes.

- Adecuación estética de naves.

- Adecuación del entorno de explotaciones ganaderas.

- Restauración de elementos singulares.

- Rehabilitación de silos.

- Creación de zonas verdes sostenibles.

- Creación de anillos verdes.

14. Pueblos en descuido y abandono.

- Restauración del patrimonio arquitectónico histórico-artístico.

- Restauración del patrimonio arquitectónico tradicional.

- Construcción de obra nueva integrada en el entorno.

- Integración paisajística de acabados exteriores inadecuados.

- Adecuación de ruinas y solares.

- Ordenación del cableado y otros elementos discordantes.

- Tratamiento de explotaciones ganaderas en suelo urbano.

- Pavimentación estética de calles.

- Adecuación paisajística de plazas y plazuelas. 
Teniendo en cuenta la importancia de la restauración vegetal en este modelo, se han seleccionado 59 especies vegetales (32 árboles y 27 arbustos) autóctonas o propias de la zona, de entre las que destacamos el pino piñonero (Pinus pinea), la encina (Quercus ilex), el almendro (Amygdalus communis), el álamo blanco (Populus alba), el chopo del país (Populus nigra) y el escaramujo (Rosa canina).

La imagen objetivo del paisaje de calidad surgido de la puesta en marcha de este modelo persigue un paisaje agrícola más diverso, infraestructuras integradas y creadoras de nuevos paisajes (Figura 3); ríos, arroyos y vías pecuarias convertidas en grandes corredores ecológicos (Figura 4); agua valorizada en sus diversas formas (ríos, lagunas, balsas de riego, etc.); un paisaje limpio sin contaminación; pueblos integrados y con abundantes zonas verdes (Figura 5) y, finalmente, un paisaje urbano cuidado con un patrimonio valorizado.
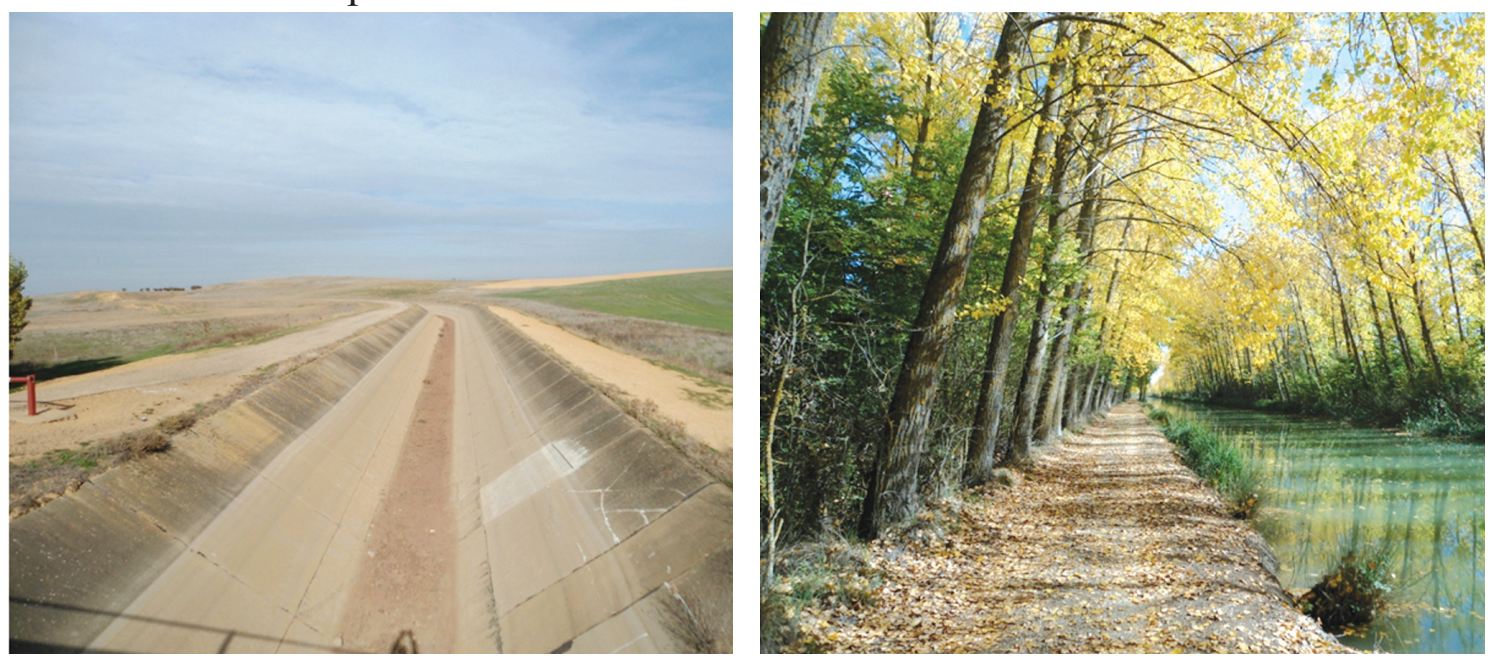

Figura 3. Oposición gráfica entre el duro canal Cea-Carrión (Villacarralón) y el canal de Castilla (Tamariz de Campos), paradigma de integración paisajística de una infraestructura.
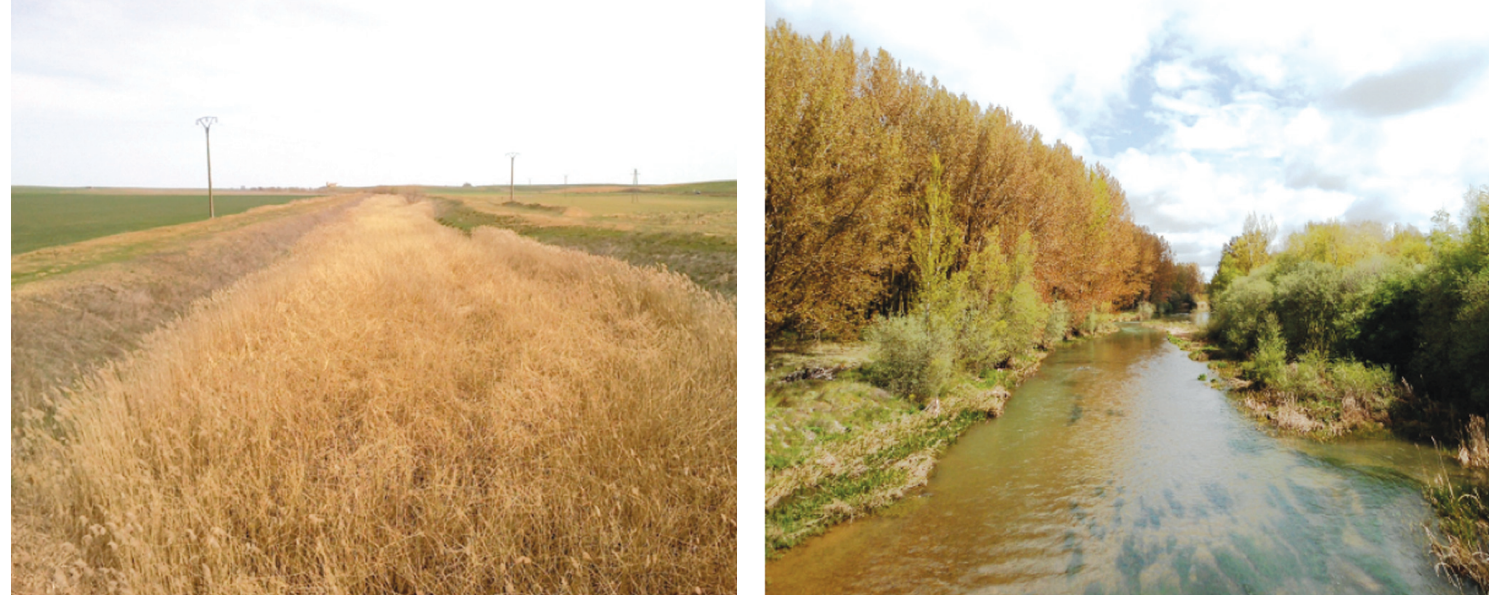

Figura 4. Contraste entre situación actual (el paisaje degradado de la ribera del Sequillo, izquierda) y situación objetivo (paisaje recuperado de la ribera del Cea, derecha). 

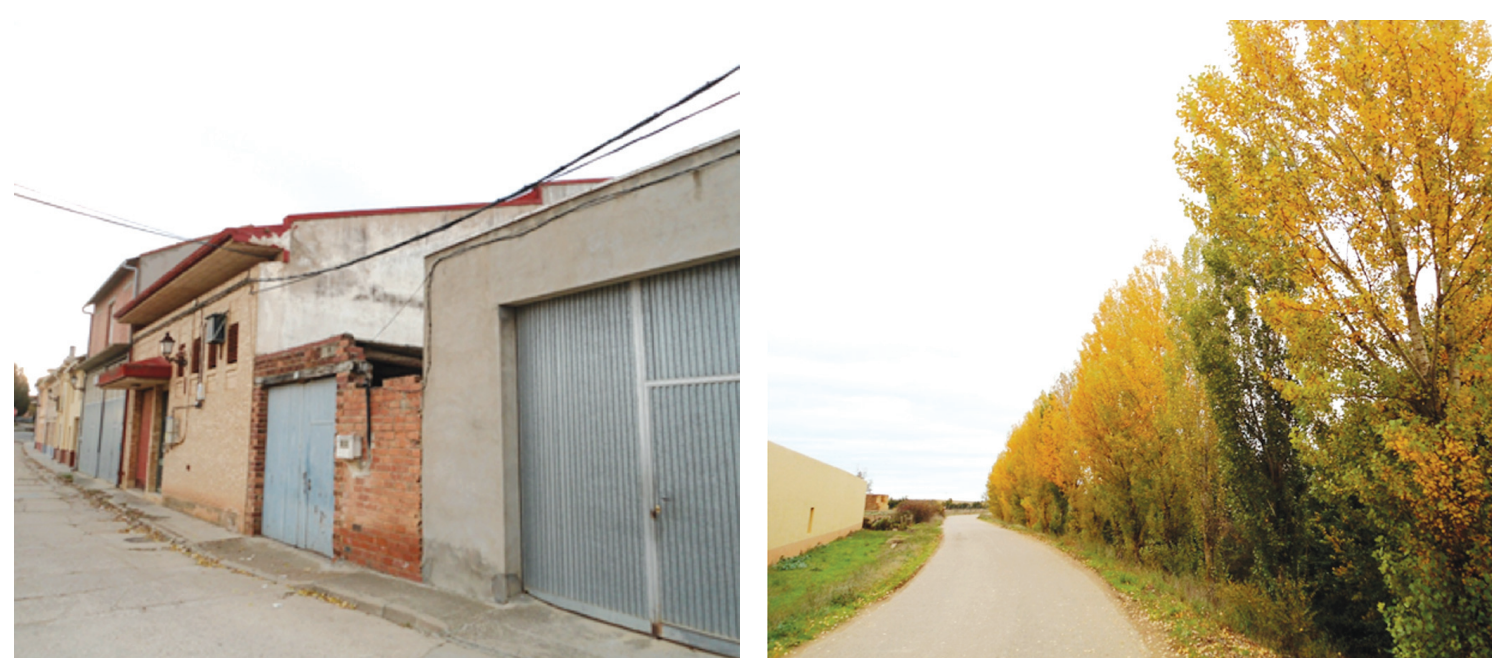

Figura 5. Imágenes enfrentadas características de espacios periurbanos en Villalón de Campos: degradación urbanística a la izquierda; integración y presencia de zonas verdes a la derecha.

El desarrollo de las actuaciones contempladas en el modelo de recuperación conllevará beneficios tales como la mejora de la calidad visual del paisaje, la disminución de su fragilidad y la reducción de impactos (Aramburu, 1993); el aumento de la biodiversidad y los servicios ecosistémicos (Barral, et al., 2015); la integración de construcciones e instalaciones voluminosas (Cañas y Ayuga, 1994; Cañas et al., 1996) o el bienestar de la población rural al estar en mayor contacto con la naturaleza (Corraliza, 2014). Es de destacar que el Canal de Castilla es el paradigma de integración paisajística y valorización de una obra de ingeniería civil en Tierra de Campos, lo cual muestra el patrón a seguir para alcanzar la imagen objetivo de calidad (Blanco, 2016).

\section{Conclusiones}

Dentro de las grandes obras analizadas, el proyecto que más ha transformado con diferencia el paisaje de Tierra de Campos es el de las concentraciones parcelarias - dado que ha afectado y simplificado toda su superficie - agrandando las parcelas, rectificando las infraestructuras y eliminando - como consecuencia- buena parte de los elementos estructurales naturales. La ejecución generalizada de este proyecto en toda la comarca, junto con la intensificación de la agricultura, han propiciado un paisaje de baja calidad visual, frágil y de muy escasa biodiversidad.

La recuperación ambiental es una técnica muy adecuada para corregir impactos y mejorar la calidad del paisaje de Tierra de Campos. En el modelo planteado se han contemplado hasta 56 actuaciones para recuperar los 14 tipos de espacios degradados. Con ello se persigue operar sobre una superficie relativamente reducida pero homogéneamente distribuida, realizando una especie de "cirugía ambiental" del territorio. Además, se ha demostrado que no es una técnica costosa, cuyo presupuesto 
medio representa tan solo el 3,48 \% del relativo a los proyectos de construcción evaluados.

Se ha constatado que existen un buen número de recursos y zonas susceptibles para valorizar el paisaje de Tierra de Campos, tanto en los espacios cotidianos (parques urbanos y anillos verdes periurbanos) como en el campo (senderos, caminos, áreas recreativas, miradores...). De todos los casos analizados, el Canal de Castilla es el paradigma de integración paisajística y valorización de una obra de ingeniería civil en Tierra de Campos.

Nuestra propuesta final es que la puesta en marcha del modelo de recuperación ambiental del paisaje de Tierra de Campos se debería hacer a través de un plan territorial, cuya promoción y gestión correspondiese a un consorcio en el que participasen varias administraciones públicas (Junta de Castilla y León, Confederación Hidrográfica del Duero, Diputaciones Provinciales, etc.). También sería posible un desarrollo gradual del modelo mediante planes municipales de recuperación del paisaje o, incluso, planes sectoriales (Medio Natural, Carreteras, Aguas, etc.).

Este modelo sería extensible al conjunto de las campiñas de Castilla y León -que ocupan 2150000 ha- e incluso a las del resto de España (casi 5700000 ha), teniendo en cuenta que las características y las degradaciones de su paisaje son muy similares.

\section{Bibliografía}

Aramburu, M.P.; 1993. Evaluación y corrección del impacto visual. Ecosistemas, 6. Tema monográfico: "Descubrir el paisaje", pp. 42-45. Asociación Española de Ecología Terrestre. Madrid.

Barral, P.; Rey Benayas, J.M.; Meli, P. y Maceira, N.; 2015. Cuantifying the impacts of ecological restoration on biodiversity and ecosystem services in agroecosystems: a global meta-analysis. Agriculture, Ecosystems \& the Environment 202: 223-231.

Benito Martín, F.; 1998. La arquitectura tradicional de Castilla y León. Consejería de Medio Ambiente y Ordenación del Territorio. Junta de Castilla y León. Valladolid.

Blanco, R.; 2016. Recuperación ambiental del paisaje de Tierra de Campos. Tesis Doctoral. Departamento de Ingeniería Agrícola y Forestal. Escuela Técnica Superior de Ingenierías Agrarias. Universidad de Valladolid.

Bolós, M.; 2005. Prólogo. En: Navés, F.; Arosamena, G.; Ruiz, B.; Martínez, C.; García, R. y Sampere, L.; 2005. Arquitectura del paisaje rural de la península Ibérica, islas Baleares y Canarias. Ediciones Omega. Barcelona.

Cañas, I. y Ayuga, F.; 1994. Agricultural buildings and landscape. Colour evaluation. XII World Congress on Agricultural Engineering. August 29 - September 1, 1994. Milano, Italy.

Cañas, I.; Ayuga, F. y Ortiz, J.; 1996. Visual impact of agricultural building on landscape: method to asses it. International Conference on Agricultural Engineering. 23-26 September 1996. Madrid, Spain.

Consejo de Europa; 2000. Convenio Europeo del Paisaje. Florencia (Italia). 
Corraliza, J.A.; 1993. Reacciones psicológicas a la estimulación escénica. Ecosistemas, 6. Tema monográfico: "Descubrir el paisaje". Asociación Española de Ecología Terrestre.

Corraliza, J.A.; 2014. Conexión entre naturaleza y bienestar. El síndrome de déficit de naturaleza. Jornades La salut i els espais naturals. 22 i 23 de setembre de 2014. Barcelona.

De Andrés, C.; Cosano, I. y Pereda, N.; 2003. Manual para la diversificación del paisaje agrario. Junta de Andalucía. Consejería de Medio Ambiente. Comité Andaluz de Agricultura Ecológica (CAAE).

Gómez Orea, D.; 2004. Recuperación de Espacios Degradados. Edit. Mundi-Prensa. Madrid.

González Bernáldez, F.; 1990. El porqué de la conservación del paisaje (hombre-ecologíapaisaje). I Jornadas sobre el paisaje. Grupo de Paisaje de la Asociación de Universitarios Segovianos. Horizonte Cultural. Segovia.

González Garrido, J.; 1941. La Tierra de Campos: Región natural. Edit. Diputación de Palencia y Ámbito Ediciones. Palencia.

Mata, R. y Sanz, C. (dir.); 2004. Atlas de los paisajes de España. Edit. Ministerio de Medio Ambiente.

Oria de Rueda, J.A.; 2007. Un mosaico de ecosistemas. En: GIL, L.; y TORRE, M.; (Eds.). Atlas forestal de Castilla y León. Edit. Junta de Castilla y León. Consejería de Medio Ambiente. Valladolid.

Rey Benayas, J.M.; Bullock, J.M. y Newton, A.C.; 2008. Creación de islotes forestales para reconciliar restauración ecológica, conservación y uso agrícola. Cuadernos de la Sociedad Española de Ciencias Forestales 28, 277-282.

Rey Benayas, J.M.; 2012. Restauración de campos agrícolas sin competir por el uso de la tierra para aumentar su biodiversidad y servicios ecosistémicos. Investigación Ambiental. Ciencia y Política Pública 4: 101-110.

Vaca, A.; 1992. La Tierra de Campos y sus bases ecológicas en el siglo XIV. Studia histórica. Historia medieval, Vol. X, pp. 149-185.

Vallerani, F.; 2008. La pèrdua traumática del sentit del 1loc: degradació del paisatge i patologies depressives. En: Nogué, J.; Puigbert, L. y Bretcha, G. (edit.) Paisatge y salut. Observatori del Paisatge de Catalunya. Generalitat de Catalunya. Departament de Salut. 
